\title{
EMPRESAS DE SALVAÇÃO LOCALMENTE GLOBALIZADAS: APROXIMAÇÕES AO ESTUDO DAS MEGA-IGREJAS EVANGÉLICAS
}

\author{
Joaquin Algranti ${ }^{1}$
}

Resumo: Os processos globalizadores no plano da cultura podem ser compreendidos inicialmente como um trabalho de rearticulação do global e do local em diferentes domínios da sociedade. Este ponto-chave de análise atinge a forma específica em que as organizaçóes religiosas produzem uma síntese histórica entre ambas as dimensóes da vida cultural. Seguindo esta perspectiva, o objetivo do presente artigo consiste em explorar os circuitos internos e externos de circulação de uma "mega-igreja" (Gramby-Sobukwe e Hoiland, 2009) evangélica em Buenos Aires, Argentina. O trabalho encontra-se dividido em três partes. $\mathrm{Na}$ primeira, propomo-nos indagar em sua estrutura de organização a partir do sistema de integração em "células". Na segunda, vamos ver como as redes internas definem três posiçóes móveis de sujeito. Por último, na terceira parte, nosso interesse se focaliza no regime de circulação que a igreja estabiliza para dentro e para fora da instituição.

Palavras-chave: neo-pentecostais, mega-igreja, circulação interna e externa

Abstract: Culture-related globalizing processes can be firstly understood as a rearticulation of both global and local elements within different society domains. This perspective reaches the specific way in which religious organizations develop a historical synthesis between both dimensions of cultural life. Following these leads this paper aims at exploring the internal and external circulation nets of an evangelical "mega-church" (Gramby-Sobukwe y Hoiland, 2009) in Buenos Aires, Argentina. The paper is divided in three parts. The first one approaches the organization's structure through "cell" integration system. The second one explores how inner nets define three mobile positions of the subject. And finally, in the third part, focuses on the circulation's pattern stabilized by the church both inside and outside of the institution.

Keywords: Neo-pentecostalism, mega-churches, internal and external circulation.

${ }^{1}$ Doctorado en Ciencias Sociales en la UBA, con una beca del Conicet (UBA/CEILPIETTE) y Profesor de la Universidad de Buenos Aires.

Debates do NER, Porto Alegre, ano io, N. I6, P. 7I-94, JUl./Dez. 2009 


\section{INTRODUCCIÓN}

Podemos comenzar delineando las coordenadas generales de un diagnóstico compartido por los estudios latinoamericanos y europeos de la globalización. Existe un relativo consenso en torno a la idea de que la modernidad, como una formación histórica delimitada, logró expresarse especialmente a través de un modo específico de organización social de las estructuras temporales y espaciales que rigen la vida en sociedad. Aquí el proceso de inscripción territorial de los Estados nacionales se construyó a fuerza de establecer fronteras geográficas y culturales, dividir internamente el territorio, consolidar centros urbanos y asegurar los medios de circulación hacia dentro y hacia afuera del país. A su vez la gestión social del tiempo apuntó a una cierta estandarización de acuerdo a los ciclos productivos e institucionales en los cuales se definían las biografías de cada persona. Desde este diagnóstico, la globalización, entendida en términos amplios como el proceso de construcción de un orden global fundado en la circulación y el intercambio tecnológico, cultural, económico y político, tiende a transformar las estructuras temporales y espaciales a las que nos tenía acostumbrado la modernidad en general y las sociedades industriales en particular. En este contexto los Estados nacionales aparecen debilitados en su capacidad de acción frente a un nuevo régimen de intercambio y redes que tiene como protagonistas a agentes trasnacionales fundamentalmente de orden económico, pero también de orden cultural, político y, como vamos a analizar en este trabajo, de orden religiosos ${ }^{2}$.

Efectivamente, algunas empresas productoras de bienes de salud y salvación logran expandir sus fronteras más allá de los límites nacionales, aceptando las reglas del intercambio que facilita la globalización. Este principio de movilidad cultural que nada tiene de nuevo para las grandes religiones de salvación como el cristianismo -ya sea en su versión católica o

2 Para una revisión teórica y metodológica de los usos y alcances del concepto de redes en los estudios sobre religiones trasnacionales ver el trabajo de Daniel Alves (2008).

Debates do NER, Porto Alegre, ANo io, N. I6, P. 7I-94, JUl./Dez. 2009 
protestantes-, se manifiesta de diferentes formas según los recursos, la historia y las estrategias institucionales con las que cuente cada grupo religiosos. Aquí cabe destacar el impulso del neo-pentecostalismo y los modelos de organización en los que logra cristalizarse. En este sentido, el artículo se encuentra focalizado sobre un tipo específico de iglesia relativamente novedosa dentro del universo evangélico, que se caracteriza por un alto nivel de circulación hacia al interior de la red de relaciones sociales que estabiliza. Nos referimos a lo que podríamos denominar, siguiendo a los estudios de Thuma y Travis (2007) y Gramby-Sobukwe y Hoiland (2009), como megaiglesias, es decir, organizaciones religiosas de grandes dimensiones con una congregación de 20.000 miembros o más, organizados hacia adentro en grupos relativamente autónomos, pero interdependientes de trabajo y en áreas o ministerios abocados a una tarea en particular -evangelización, coro, asistencia social, consejería, deportes, medios de comunicación etc.- Estas iglesias presentan una compleja red de relaciones internas con sus sistema de autoridad y estructuras de gobierno. Generalmente, se trata de organizaciones trasnacionales que participan de los circuitos externos de difusión y financiamiento, pese a que conservan una autonomía económica. Uno de sus rasgos distintivos de alguna de ellas consiste en el trabajo sistemático de formación de líderes religioso, ofreciendo de forma gratuita espacios de enseñanza y canales de promoción para los creyentes que intenten profesionalizarse en el "Evangelio".

En la Argentina existe, especialmente a partir de la década del noventa, una consolidación importante de las mega-iglesias dentro de los circuitos formales e informales, en el marco de un crecimiento general del mundo evangélico ${ }^{3}$. Algunas de ellas tienen que ver con organizaciones religiosas extranjeras que colocan nuevas sedes en nuestro país, como la Iglesia Universal del Reino de Dios -IURD- o Deus é amor, bajo un modelo corporativo de

3 Según la encuesta nacional realizada en el 2008 por el área de "Sociedad, cultura y religión" del CONICET, los evangélicos representan hoy el $9 \%$ de la población, en un contexto cultural marcado fuertemente por la presencia del catolicismo con un 76,5\% y un número importante de indiferentes religioso que llega al 11,3\%. Estas cifras colocan a los evangélicos como la primera minoría religiosa en nuestro país.

Debates do NER, Porto Alegre, ano io, N. I6, P. 7I-94, JUl./Dez. 2009 
expansión religiosa (Oro \& Steil, 1997). Otras responden, por el contrario, a experiencias nacionales de una segunda generación de líderes. Siguiendo una tendencia que se repite en numerosos países latinoamericanos, estas mega-iglesias comparten una orientación evangelizadora dirigida hacia la clase media y media alta de Buenos Aires. En la presente investigación nos proponemos trabajar con un templo en particular en donde esta orientación de clase se expresa con más fuerza: nos referimos a la iglesia evangélica de Rey de Reyes. El artículo apunta a estudiar los circuitos de circulación que estabiliza la iglesia hacia adentro de sus organizaciones, fijando posiciones diferenciales de sujetos que contribuyen a la socialización del creyente, y hacia afuera de ellas, creando redes trasnacionales de intercambio con otros centros. Ambas son expresiones singulares de una síntesis entre lo global y lo local. El trabajo se inscribe en el marco de un proyecto de investigación de doctorado que incluye entrevistas en profundidad, observaciones participantes y el análisis de documentos de la iglesia señalada.

\section{UNA ESTRUCTURA EN MOVIMIENTO}

Como toda institución las mega-iglesias delimitan un espacio de relaciones sociales estructurado a partir de criterios propios en donde se definen posiciones de autoridad que contribuyen a la organización interna de sus miembros. Pertenecer a Rey de Reyes, al Centro Cristiano Nueva Vida o a la Catedral de la Fe significa inscribirse, en primera instancia, en una red de vínculos ordenados por un criterio de "autoridad espiritual", que reposa en un conjunto de principios, atributos y calificaciones religiosas. Una de las experiencias primarias del sujeto que comienza a socializarse en el ámbito evangélico, consiste en aprender quienes son sus referentes cercanos en términos afectivos, pero también en términos de rango y obediencia. $\mathrm{Nu}$ merosos especialistas clásicos y contemporáneos sobre el pentecostalismo señalan la naturaleza jerárquica de sus relaciones sociales, es decir, el modelo de autoridad vertical que sostienen los templos. Las mega-iglesias no son la excepción. En este sentido es preciso describir el sustrato material que

Debates do NER, Porto Alegre, Ano io, N. I6, P. 7I-94, JUl./Dez. 2009 
actúa de soporte de la vida colectiva, configurando criterios de organización y distribución de las poblaciones. En el presente apartado nos proponemos caracterizar la morfología (Mauss, 1979,p.360) del grupo religioso a través de su estructura jerárquica, atendiendo especialmente a la estrategia de organización comunitaria que configura el sistema celular. La opción por este sistema expresa la respuesta de la iglesia al desafío de crecer de modo continuo, conteniendo y consolidando a los creyentes en diferentes espacios de inserción, dado que se trata de un modelo de integración comunitaria basado en múltiples formas de pertenecer. También expresa la versatilidad de la estructura organizativa del neo-pentecostalismo que redefine sus estrategias institucionales de acuerdo a una nueva meta orientada a la integración activa de sus miembros, capitalizando sus habilidades, saberes y destrezas.

El punto de partida de la organización celular remite a la pregunta primera por el perfil o tipo de asociación religiosa que se intenta establecer en un momento determinado. El co-pastor Sergio, encargado del Ministerio de Jóvenes, explica la tensión entre iglesia y movimiento con toda claridad:

Una iglesia puede ser un movimiento o una iglesia. El movimiento es cuando vos tenes un lugar que hay una sola cabeza visible, llamémosle un protagonista, alguien convoca, la gente entra, sale, va viene y hay toda una rotación de gente pero nadie se conoce entre si, no hay digamos amistad, no hay un sentido de pertenencia, no hay comunión...entonces, es un movimiento y punto. Si vos miras un poquito las caras que estuvieron ayer no son las caras que están hoy, el lugar está siempre lleno, pero no son los mismos porque la gente siente que suple una necesidad que es la de recibir, pero no es un lugar en donde pueda andar ni es un lugar donde pueda expandirse hacia los costados. Nadie los conoce, no conoces a nadie, no hay algo personalizado. ¿Viste como las empresas que te dan un servicio personalizado? Entonces, la iglesia brinda todo eso, en un sentido. Te conoces, te conocen, perteneces, te comunicas, te contienen, te aconsejan, no tenés un solo referente, tenés muchos referentes a nivel liderazgo. Eso se da a través de la célula.

El sistema de organización celular no es una creación de Freidzon, sino que tiene que ver con el intercambio de experiencias internacionales y la 
circulación de saberes especializados que promueve el neo-pentecostalismo a través de conferencias, encuentros, reuniones y actividades. En este caso los modelos exitosos de aplicación del sistema refieren a la experiencia colombiana del pastor Cesar Castellanos y la del pastor coreano David Yonggi Cho. Naturalmente, la versión que se actualiza en Rey de Reyes adopta rasgos locales de acuerdo a la impronta de sus pastores. Como señala el co-pastor Pablo:

El método de Colombia, lo que ellos hacen es hacer mucho énfasis en formar líderes y formar discípulos, ¿̇no? En el caso nuestro, nosotros hacemos más énfasis en la persona y dejás que el crecimiento sea naturalmente. Sí rescatamos el tema de los grupos, rescatamos el tiempo que uno tiene que dedicarle a la persona para que crezca en su fe, para enseñarle la palabra, pero nuestro objetivo, no es que todas las personas que vengan a la iglesia terminen siendo un líder más, sino que nuestro objetivo es que todas las personas que vengan a la iglesia sean verdaderos cristianos, ¿no? Que tengan su compromiso y cuando ellos tienen su compromiso, tienen su encuentro con Dios, el resultado es siempre el deseo de hacer algo.

Queda claro que la organización de las multitudes dispersas en grupos pequeños no tiene que ver solamente con criterios de gobierno, sino también $y$, especialmente, con el desarrollo de un cierto tipo de lazo social basado en el mutuo conocimiento, la pertenencia y los vínculos afectivos que permiten transformar a la multitud en lo que la sociología clásica denomina con el termino de comunidad. Las células son los espacios mínimos de interacción que ofrece Rey de Reyes a su comunidad. Los criterios de división de las células son por género, edad, estado civil y tareas desempeñadas en la institución; es por eso que existen múltiples ámbitos de inserción para el recién llegado según su situación personal. Hay células de adolescentes, jóvenes y ancianos, divididos en hombres y mujeres, también hay grupos para nuevos matrimonios y ya consolidados y células mixtas según las actividades de los creyentes en los distintos ministerios. Existen alrededor de 2.400 células inscriptas de las cuales aproximadamente 1.100 pertenecen al área de jóvenes entre 12 y 33 años, 900 al grupo de mujeres de 30 a 55 y 400 a hombres

Debates do NER, Porto Alegre, Ano io, N. I6, P. 7I-94, JUl./Dez. 2009 
adultos del mismo rango etario. Como queda en evidencia el núcleo más importante de la congregación son los jóvenes, divididos por género y con una mayoría femenina, seguido de las mujeres adultas. Por último aparecen los hombres entre 30 y 55 años como la población más difícil de captar y también de conservar no sólo para Rey de Reyes, sino también para todo el universo evangélico.

Resumiendo, el sistema celular plantea una morfología de la comunidad en donde la "conducta pastoral", en términos de un modelo de interacciones duraderas basadas en círculos reducidos de sociabilidad y mutuo conocimiento, atraviesa toda la vida del templo generando esquemas compartidos de percepción y disposición. En esta red de relaciones se configuran tres posiciones claramente definidas en el espacio social de las mega-iglesias: nos referimos al núcleo duro, los cuadros medios de líderes y la comunidad periférica. A continuación vamos a caracterizar a cada una de ellas analizando los circuitos internos de circulación en los que se desenvuelven.

\section{LAS REDES INTERNAS: TRES POSICIONES MÓVILES DE SUJETO}

\section{A. El núCleo duro}

El modelo de organización celular conserva una jerarquía interna dentro de la cual podemos reconocer a los círculos más reducidos de autoridad en donde se concentran las decisiones sobre el manejo de los recursos, la organización y proyección de los ministerios, así como también las nuevas orientaciones o proyectos de largo plazo en los que se embarca la iglesia. A esta descripción -que bien podría corresponderle a una empresa o a un departamento público- le falta por supuesto la dimensión fundamental de lo sagrado, es decir, los bienes de salvación y de salud que supone ocupar el status de pastor y su círculo de pertenencia. En este sentido, el núcleo duro concentra al menos dos formas de carismas: el carisma objetivo que otorga el ejercicio de la función pastoral, bajo el respaldo de los circuitos de for- 
mación, pero principalmente a partir del reconocimiento de los pares; y el carisma subjetivo relacionado a las habilidades diferenciales propias de cada especialista en las que no sólo se destacan los dones de sanidad y profecía, sino también otros carismas como la sabiduría, la claridad, el humor o la unción en las prédicas. Naturalmente estas dos formas de manifestación de lo sagrado pueden entrar en conflicto; de hecho, las posiciones en las que se concentra las diferencias suelen ser la comunidad periférica y, en menor medida, los cuadros intermedios. A su vez, este grupo selecto de especialistas religiosos presenta rasgos interesantes en relación a la clase social de origen y los circuitos de formación evangélica. Profundicemos un poco en estos rasgos.

Con respecto al primero es importante señalar que Rey de Reyes, como otras mega-iglesias, se encuentra orientada hacia el amplio espectro de la clase media Argentina. Esto no quiere decir que su base social sea únicamente de clase media, sino que la imagen de si que proyecta el templo en sus edificios, sus representantes y las practicas rituales que sostienen, coinciden con los estilos culturales (Douglas, 1999, p.13-19) propios de un sector definido de la sociedad. Aquí los pastores son un fiel reflejo de esta orientación. Si nos atenemos al nivel socioeconómico y al nivel de instrucción, nos encontramos con que la clase social de procedencia concierne a lo que podríamos denominar como el sector medio de la clase media. De hecho podríamos ampliar esta tendencia más allá de los pastores hacia toda la estructura permanente del templo e, incluso, hacia los líderes y Timoteos, pese a que este sector al igual que la comunidad periférica adopta una composición heterogénea marcada por la presencia dominante de los sectores populares. Es interesante señalar la paradoja de una institución cuyos líderes poseen una identidad de clase que no se corresponde directamente con la de sus fieles. La dimensión simbólica relacionada a la posibilidad de pertenecer a una iglesia que reposiciona a los sujetos en un universo de prácticas y símbolos propios de una clase social más favorecida, constituye un elemento clave que define la identidad y el atractivo de Rey de Reyes.

Los circuitos de formación religiosa constituyen el segundo rasgo distintivo del círculo pastoral. El perfil del especialista que propone la

Debates do NER, Porto Alegre, ANo io, N. I6, P. 7I-94, JUl./Dez. 2009 
iglesia se recuesta en las instancias formales de capacitación dentro de las instituciones portadoras de un capital simbólico legítimo, históricamente acumulado, como son los casos del Instituto Bíblico del Río de la Plata o la Vision International University. A diferencia del otros pastores que encarna un modelo de autoridad religiosa fundado en la experiencia de vida dentro de los márgenes de las instituciones evangélicas e incluso de la ley, aquí se propone un modelo pastoral que se ajusta a las exigencias de una carrera con su correspondiente formación académica, complementada con el trabajo practico, rotativo y constante en las áreas de la iglesia. El círculo de mayor jerarquía en la iglesia combina la formación teología y pastoral con el desarrollo de una carrera, en términos de apuestas, aprendizaje y crecimiento, dentro de la misma institución religiosa.

Dentro del espacio de posiciones posibles de la iglesia, el núcleo duro representa el círculo de mayor intercambio y acceso a, por lo menos, tres tipos de flujos internacionales que ofrece el universo neo-pentecostal. Nos referimos a: 1) la posibilidad de formación teológica en instituciones universitarias extranjeras; 2) la participación en actividades, conferencias y seminarios especializados en las áreas ministeriales de la iglesia, tales como juventud, asistencia social, liderazgo, consejería etc. y 3) el trabajo de evangelización y prédica a través de una red de intercambio con iglesias de América, Europa y África. Como vamos a ver más adelante ésta última función se encuentra restringida casi exclusivamente a las figuras carismáticas del matrimonio Freidzon, a través de una carrera reorientada hacia las actividades evangelísticas. El contacto con los tres tipos de flujos internacionales supone signos de distinción que refuerzan, a través del juego del reconocimiento externo e interno, las posiciones de autoridad diferenciales que distinguen a este grupo, de los cuadros medios y la periferia institucional. Por eso, no es de extrañar que los miembros del núcleo duro hagan gala de sus relaciones con creyentes profesionalizados en la fe que ocupan posiciones análogas en otras iglesias alrededor del mundo; después de todo, un pastor argentino tiene más cosas en común con un pastor de Colombia, Brasil, España o Corea que con un miembro periférico de su propia iglesia. 


\section{B. LOS CUADROS MEDIOS Y SU CONDICIÓN INDETERMINADA}

Las mega-iglesias son empresas de salvación que dependen en parte de construir activamente cuadros medios, sin descuidar las instancias previas de formación doctrinal. En este sentido el proceso de institucionalización del carisma adopta en Rey de Reyes una forma definida: el trabajo invisible de una red jerárquicamente estructurada de líderes ocupados en las cuestiones cotidianas del pastoreo es la condición de posibilidad para que el pastor principal renueve su autoridad carismática desde la distancia y los recursos que ofrece una estructura permanente, con sus ritmos y dinámicas propias. Los líderes y los Timoteos representan el 18,8 \% de la población total de la iglesia (22.000 miembros). Ahora bien, esta división social del trabajo religioso plantea sin embargo tensiones relacionadas con la posición ambigua de los cuadros medios que se encuentran ejerciendo un rol de influencia sobre su grupo, sin contar con los beneficios plenos, tanto materiales como simbólicos, que la institución ofrece a los círculos de mayor jerarquía. Para sondear el alcance de esta contradicción es preciso comprender cuales son las ventajas y los peligros de formar líderes.

Podemos sistematizar los beneficios del liderazgo en dos niveles analíticos: la institución y los sujetos. Para la iglesia la formación de líderes contribuye a organizar a la comunidad religiosa, configurando una forma dinámica de gobierno más cercana a la lógica empresarial, o en su defecto, a la nueva gestión publica, que a la dominación burocrática tal como la concibiera Weber. Las ventajas de trabajar en el empoderamiento de los niveles subalternos permite: 1) capitalizar los recursos humanos de la congregación, potenciando los conocimientos y saberes previos de los creyentes, 2) obtener un alto compromiso por un bajo costo dado que la tarea del líder es voluntaria, 3) descentralizar las responsabilidades pastorales diversificando la oferta de células. 4) fomentar la homogeneidad de la doctrina en las tres funciones que identificaba Joachim Wach, esto es en relación a la explicación y articulación de las creencias, la regulación normativa de los cultos y las relaciones diferenciales con otros conocimientos, 5) construir unidades ejecutivas capaces de llevar a cabo tareas y objetivos específicos.

Debates do NER, Porto Alegre, Ano io, N. I6, P. 7I-94, JUl./Dez. 2009 
En contrapartida los creyentes que eligen el camino del liderazgo también obtienen ventajas importantes. Reciben formación religiosa en la Escuela de líderes durante un año, participan de reuniones especiales, acceden a una red de contacto con autoridades que se encuentran en una posición más alta como los supervisores o, incluso, pueden alcanzar al círculo de los pastores y los ministerios. En fin, se abre la posibilidad de llevar a cabo una carrera interna dentro del espacio de relaciones y posiciones objetivas que estabiliza la institución, como un microcosmos social con sus reglas, dinámicas y circuitos oficiales de crecimiento.

La posición religiosa del líder también es portadora de contradicciones objetivas vinculadas al alcance, las atribuciones y los limites de su rol en la iglesia. Aquí el liderazgo habilita el aprendizaje y la aplicación sistemática de técnicas de pastoreo, como una de las tecnologías de poder más antiguas que identificaba Michel Foucault (1992,p.270-273) en el arte de conducción de los sujetos. El trabajo de dirección de la célula hace de cada líder un pastor en potencia, reconocido en su grupo por sus atributos religiosos: la capacidad de orar y trasmitir la Palabra, el conocimiento de la Biblia y lo que los creyentes denominan en términos generales como el "amor por las cosas de Dios" para referirse a la identificación con los valores de una vida cristiana y el modo en que estos se hacen visibles en las acciones del líder. Podemos plantear que su situación es estructuralmente ambigua dado que se encuentran cerca de las bases, conocen sus necesidades y problemas, pueden influenciarlos en las decisiones cotidianas incluso más que los pastores oficiales, pero no cuentan con el sostén económico de la iglesia ni con el prestigio, es decir, con el peso simbólico de las autoridades carismáticas. El peligro de formar líderes radica naturalmente en la división de la comunidad, en la disgregación de la estructura jerárquica en grupos intermedios que responden al líder local, por sobre las autoridades oficiales, consagradas, del templo.

Esta posición estructuralmente ambigua e indeterminada, restringida a operar en la zona intermedia de la semi-profesionalización en la fe, tiende a construir redes con las posiciones superiores e inferiores en las jerarquías del templo. Hacia "arriba", con el núcleo duro, intenta participar de los espacios de decisiones y acceso a recursos, homologando la figura de los pastores y los

Debates do NER, Porto Alegre, ano io, N. I6, P. 7I-94, JUl./Dez. 2009 
signos de distinción que otorgan en parte los flujos internacionales. Apostar a la formación teológica, invertir en seminarios de capacitación con figuras extranjeras, colaborar en la organización de eventos masivos y conocer la literatura cristiana de referencia mundial que manejan las autoridades. Las relaciones con el núcleo duro son casi siempre conflictivas y plagadas de obstáculos debido al carácter exclusivo de su posición. Hacia "abajo", con las células, los cuadros medios reproducen un modelo de liderazgo pastoral en el que se pone en juego el universo de referencias transnacionales del núcleo duro. Aquí los objetos de consumo cultural cristiano -pensemos, por ejemplo, en libros, CDs, videos, películas, música, revistas, diarios etc.- y su circulación contribuyen a reforzar un lenguaje compartido, desterritorializado, un paisaje religioso para utilizar la expresión de Rita Segato (2008,p.50) en diálogo con los análisis de Arjun Appadurai (2001). Como un "pastor en miniatura" las posiciones de liderazgo de los cuadros medios adquieren su mayor movilidad con los miembros periféricos, que vamos a analizar a continuación.

\section{LA PERIFERIA INSTITUCIONAL}

Si el núcleo duro de los pastores, seguidos por los líderes de célula y los Timoteos, define las posiciones internas dentro de los círculos de autoridad de la iglesia, el grueso de la congregación -o sea, unos 17.000 creyentes- se ubican dentro del amplio espectro de lo que nos proponemos denominar con el término de periferia institucional, cuando priorizamos la perspectiva de la institución, o comunidad periférica, cuando elegimos la visión de los actores. Utilizamos el concepto de comunidad, a sabiendas de la carga histórica que posee en la sociología, para dar cuenta de la importancia del lazo afectivo en la construcción de las relaciones sociales y para enfatizar la dimensión de la pertenencia a un "Nosotros" que funciona como un poderoso anclaje identitario que le permite al sujeto hablar de si mismo y de su entorno. A su vez, el carácter periférico de la comunidad refiere a una forma específica de relación de la institución con los creyentes y de los

Debates do NER, Porto Alegre, Ano io, N. I6, P. 7I-94, JUl./Dez. 2009 
creyentes con la institución. Del lado de la mega-iglesia se trata de establecer una zona intermedia, flexible, incluso de indefinición, en donde es posible pertenecer y reconocerse en el "Evangelio" sin cumplir en su totalidad con las restricciones religiosas y las exigencias de un modelo de vida cristiano. Del lado del sujeto es la posibilidad de negociar su identidad, estableciendo una relación lúdica, cambiante, ambigua, con los marcadores identitarios de la iglesia. Se trata de una posición interestructural, siguiendo los estudios de Víctor Turner (1999, p. 103), en donde el creyente habita los contorno entre el adentro y el afuera de la institución. Naturalmente el carácter liminal no adopta las características definidas propias de una sociedad estable y de pequeña escala, pero es posible reconocer un estado de transito en los dominios de la periferia, por lo menos en los términos en que Rey de Reyes define las formas de pertenencia. En este sentido y comparados con los círculos de autoridad, la posición periférica habilita un mayor margen de acción en el juego de las apropiaciones de símbolos y prácticas.

La estructura de organización de las mega-iglesias delimita un espectro de posiciones posibles que hacen a la construcción activa por parte del templo de una periferia institucional. Lejos de constituir una excepción al modo de ser religioso, la periferia es una de las condiciones de posibilidad indispensable de la supervivencia institucional de un grupo determinado. De hecho la posición jerárquica de la autoridad religiosa se configura en el juego de relaciones que lo diferencian y lo igualan con su grey; los más santos, los más puros, los más cercanos a Dios, necesitan de los más débiles de espíritu, o sea, de una comunidad que los reconozca y los confirme en su santidad. La periferia es aquella zona gris en donde la participación y la creencia se vuelven intermitentes, selectivas, complementarias. Es el espacio en donde se conjugan las figuras del peregrino y el convertido, siguiendo a Hervieu-Léger (2004), donde se consolidan procesos de individuación del creer, como señala Fortunato Mallimaci (2008, p. 128) al referirse a la "religión difusa", al "creer sin pertenecer" o a los "católicos a mi manera".

Para el mundo evangélico son los cristianos que asisten a más de un templo a la vez, combinando múltiples pertenencias institucionales o los que mantienen prácticas de raigambre católico, participan de peregrinaciones,

Debates do NER, Porto Alegre, ano io, N. I6, P. 7I-94, JUl./Dez. 2009 
adoran a santos y vírgenes; o aquellos que recurren a los curanderos, a las terapias alternativas -yoga, reiki, reflexología etc.- o simplemente conservan la fe en las creencias autóctonas del país; son los que acompañan a un familiar o a un amigo evangélico, los que se encuentran en el proceso de conversión pero que todavía no realizaron el bautismo público, ni participaron de los encuentros espirituales; también los que pese a haber cumplido con estos pasos litúrgicos asisten de forma discontinua a las reuniones de célula o a la Escuela de Vida. Y, por último, los creyentes que, habiendo incorporado los esquemas de percepción y disposición del neo-pentecostalismo, optan por una experiencia solitaria, profundamente espiritual de la fe. En todos los casos, las conductas que priorizan la complementariedad, las combinaciones y la reapropiación selectiva por sobre los modelos más o menos estandarizados de las mega-iglesias, no refieren, en última instancia, a una condición ontológica del sujeto, sino a la misma experiencia histórica de un individuo que en los diferentes planos de la vida cotidiana -el trabajo, los afectos, el tiempo libre, el consumo etc.- despliega estrategias de negociación y distanciamiento. La periferia, como un espacio de relaciones dinámicas, es constantemente redefinida dado que representa el punto de encuentro entre el modelo de identidad cristiana que construye la institución y las formas subjetivas de apropiación del sistema de creencias. Su carácter es siempre relacional, depende del juego de continuidades y rupturas tanto con la figura del especialista religioso como con la del hombre de la calle ajeno a los principios cristianos.

Aquí el rol de los flujos internacionales obedece a las posibilidades de acceso que otorga la iglesia como un ámbito de tránsito, es decir, de concentración y circulación de símbolos, discursos, objetos, personas e imágenes que contribuyen a estabilizar un cosmos religioso definido. Las posiciones periféricas son las que cuentan con mayor libertad para llevar a adelante una apropiación selectiva de la oferta cultural que reúnen las instituciones. Asistir, por ejemplo, a la campaña del evangelista Luis Palau o Benny Hinn, participar de los cultos de distintas iglesias cuando vienen pastores renombrados, presenciar recitales, seminarios o charlas motivadoras, consultar libros especializados, escribir en blogs evangélicos, escuchar prédicas grabadas y

Debates do NER, Porto Alegre, ANo io, N. I6, P. 7I-94, JUl./Dez. 2009 
programas de radio, ver los programas de la IURD en televisión o realizar cursos y talleres específicos (de idiomas, oratoria, cocina, administración del dinero, etc.). Desde una posición de consumidor más que de productor, la periferia institucional está en condiciones de reconstruir a gusto el universo de bienes culturales que las iglesias ponen a su disposición. Esto da lugar naturalmente a interpretaciones heterodoxas -desde el punto de vista del núcleo duro- del mensaje evangélico y sobre todo de las prácticas y los usos de los carismas. Más allá de los posibles conflictos, la selección y reapropiación de los bienes culturales cristianos establece una forma de socializarse en el "Evangelio" participando del régimen de circulación e intercambio de recursos.

\section{"ESTAR EN MOVIMIENTO”: SOBRE EL RÉGIMEN DE CIRCULACIÓN E INTERCAMBIO DE RECURSOS}

Uno de los principios básicos que promueve la praxis religiosa en mega-iglesias como Rey de Reyes y dentro del neo-pentecostalismo en general consiste en el principio de circulación e intercambio de todo tipo de recursos (materiales, simbólicos, prácticos, sociales, afectivos, etc). Aunque relegada esta clave de análisis tiende a aparecer generalmente en las investigaciones que problematizan la función del dinero en la teología de prosperidad, como son los estudios sugerentes de Ari Oro (1992) Nicolás Guigou (1993), Ricardo Mariano (1996), Patricia Birman (2001), Pablo Semán (2001) y Enzo Pace (2006). En el presente apartado vamos a trabajar con el régimen de circulación que atraviesa a las tres posiciones mencionadas en el punto dos, contribuyendo a afianzar las redes internas en las que se socializa el creyente. Si bien lo social no puede ser reducido a las estructuras del intercambio como planteaba Lévi-Strauss, esta dimensión posee un rol destacado en las organizaciones religiosas, que es preciso tener en cuenta (Godelier, 1998:31-34). A partir de aquí vamos a ver que los flujos de circulación que se estabilizan hacia adentro de la iglesia les permiten a su vez proyectarse

Debates do NER, Porto Alegre, ano io, N. I6, P. 7I-94, JUl./Dez. 2009 
hacia afuera, convirtiendo a Rey de Reyes en una organización de carácter trasnacional.

Las entrevistas realizadas durante el trabajo de campo muestran que todos los entrevistados sin excepción participan de alguna instancia, aunque sea en los márgenes de la iglesia. Desde el momento en que el individuo comienza a "entrar en el Evangelio", esto es, en un universo de prácticas y representaciones que redefinen la forma de ver, hablar y relacionarse con el cuerpo, la circulación de recursos se convierte en una necesidad dado que es el medio por el que se activan las fuerzas espirituales. La resocialización del sujeto se sostiene, en parte, en un régimen de circulación continua. Lo que se intercambia son recursos en un sentido amplio del término. Se trata en primera instancia de tiempo, voluntad, dedicación, ganas, dinero (ofrendas y diezmo), ritos y "Palabras" - pasajes de la Biblia-, como la forma más sencilla y básica de intercambio, y a medida que el creyente se afianza las prestaciones se convierten en saberes, conocimientos, responsabilidades, tareas específicas y compromisos con otras personas. El sentido de la donación que se establece con el grupo pequeño de la célula y con la comunidad ampliada del templo produce dos tipos de reciprocidades complementarias. La primera, tiene que ver con el acceso material a una red interna de servicios que incluye bolsas de comida, ropa, medicamentos, actividades gratuitas, cursos de capacitación, catequesis, asistencia psicológica, contactos laborales y ámbitos específicos de colaboración (coro, deportes, ayuda social etc.). La reciprocidad que la institución media a través de sus representantes consiste justamente en esta red ampliada de servicios en donde la participación aparece como una moneda de cambio fundamental para el acceso. La segunda, apunta a la reciprocidad en términos cosmológicos. La acción de dar en cualquiera de sus formas pone en movimiento fuerzas espirituales que se traducen en bendiciones. Para el cristiano la promesa de Dios es la cobertura en todas las áreas de la vida -material, espiritual, familiar, afectiva, profesional, física etc.- a partir de la bendición. Por eso toda entrega tiene sus contraprestaciones bajo los múltiples medios con los que la divinidad cuenta para bendecir, recompensar, al creyente por su actitud. En el mundo evangélico los bienes sagrados circulan constantemente y la

Debates do NER, Porto Alegre, ANo io, N. I6, P. 7I-94, JUl./Dez. 2009 
mejor manera de crecer en prestigio y autoridad espiritual es entregar lo que cada uno tiene a la obra de Dios. En este sentido no es raro que una de las conductas más criticadas dentro de los espacios de formación de la iglesia sea la de los llamados "calienta sillas". Si el principio de circulación es uno de los fundamentos sobre los que se resocializa al sujeto, es esperable que la figura negativa de este proceso corresponda a la actitud tibia, indefinida, de los que ocupan un lugar sin apropiárselo. Esta figura suele estar asociada a los grupos más alejados dentro de la periferia institucional. De hecho, podemos reconocer formas diferenciales de intercambio, en términos de intensidad, frecuencia y recursos en juego, según la posición que se ocupe en las redes de la iglesia. Las variaciones del intercambio religioso adoptan rasgos específicos dentro del núcleo duro de los pastores, en los cuadros medios de los supervisores, líderes y Timoteos y en el entramado complejo que constituye la comunidad periférica. En cada uno de estos dominios el sistema de prestaciones varía no en los principios, los significados, que moviliza, sino en el modo en que se llevan a acabo en la práctica siguiendo el sentido de las reglas, las estrategias y las apuestas propias de cada posición (Bourdieu, 2007, p. 158).

El régimen de circulación interno en el que se intercambian dones y contra-dones, nos permite reconocer una fuerte correspondencia entre tres niveles complementarios de toda religión: nos referimos al juego de articulaciones que se establecen entre la "morfología", la "cosmología" y las "posiciones del sujeto". En el nivel morfológico se estabiliza una estructura de organización fundada en múltiples y variados espacios de pertenencia, definidos justamente por la facilidad de circulación entre los grupos de trabajo, los ministerios y las actividades. La estructura se presenta de forma flexible y cambiante, como una estructura en movimiento que promueve el tránsito de los creyentes. A su vez, en el nivel cosmológico, los principios espirituales que sostiene el neo-pentecostalismo refuerzan, como vimos, la importancia de la entrega -de tiempo, conocimientos, disposición, ofrendas etc.- para activar el intercambio con el mundo espiritual. Aquí las posibilidades de bendición, en un sentido amplio, son inseparables de la reciprocidad que compromete al cristiano con la donación de los recursos con los que cuenta

Debates do NER, Porto Alegre, ano io, N. I6, P. 7I-94, JUl./Dez. 2009 
en cada momento. El intercambio inicia un ciclo que culmina indefectiblemente con algunas de las formas de la bendición. Por ultimo, en el nivel de las posiciones del sujeto, también nos encontramos con el régimen de circulación. Ya sea que nos concentremos en el núcleo duro, en los cuadros medios o en la comunidad periférica, la idea de un crecimiento constante que lleva a aceptar nuevos desafíos, capacitarse y trabajar en áreas diferentes impulsa a la rotación dentro del templo. En correspondencia con la morfología y la cosmología, las posiciones de sujeto tienden a ser móviles y la movilidad se alimenta de la donación de todo tipo de recursos, como el motor que le permite al cristiano iniciar una carrera profesional en el mundo religioso. El pasaje de converso, a miembro de célula, después a Timoteo, luego a líder, a supervisor, a jefe de ministerio e, incluso, si se dedica tiempo completo a co-pastor de la iglesia, lleva implícito el régimen de intercambio en donde el cambio de posiciones depende, en parte, de "la entrega" del creyente. De este modo, es posible reconocer un alto nivel de correspondencia entre la estructura social del templo, el universo simbólico que recrea y el lugar que le otorga al individuo.

Es importante retener este criterio de funcionamiento institucional dado que sus consecuencias pueden ir mucho más allá de la vida religiosa. De hecho, la estructura que pone en marcha la iglesia habilita múltiples y cambiantes formas de intervención en la sociedad, dentro de las cuales la política partidaria, el Estado o la sociedad civil pueden pasar fácilmente al centro de la escena. A continuación vamos a analizar el modo en que estas redes que en un principio son internas tienden a proyectarse hacia afuera del templo a los dominios del "mundo", de la sociedad, y hacia los circuitos religiosos internacionales en los que Freidzon es portador del "avivamiento" religiosos de la Argentina.

\section{PROYECCIONES NACIONALES E INTERNACIONALES}

Sabemos que las mega-iglesias delimitan un espacio definido de relaciones sociales en base al sistema de células, sabemos que allí se estabilizan

Debates do NER, Porto Alegre, Ano io, N. I6, P. 7I-94, JUl./Dez. 2009 
diferentes posiciones de sujeto, es decir, formas de pertenecer y ocupar un lugar en la institución, y también sabemos que el régimen de circulación e intercambio de recursos contribuye a crear redes internas de socialización. Nos encontramos ante una organización religiosa de gran escala que reúne y capitaliza un conjunto variado de habilidades, destrezas, conocimientos y aptitudes que se pueden poner en juego más allá de la geografía específica de su territorio. Rey de Reyes funciona como una iglesia "hacia afuera" en dos sentidos complementarios: en primer lugar, como un agente que consume, pero también produce activamente bienes simbólicos religiosos, bajo la forma de objetos, discursos y símbolos relacionados a figuras carismáticas. Es así que el templo actúa como un centro de difusión de productos culturales cristianos que importan, por ejemplo, las editoriales Peniel o Certeza. A su vez, es posible identificar un trabajo sistemático de proyección de sus máximos referentes -el matrimonio Freidzon- hacia numeroso países, consolidándolos como representantes del "mover espiritual" de la Argentina frente al mundo. En segundo lugar, la iglesia extiende sus redes internas de organización en el ámbito local, a través de ministerios específicos dedicados a intervenir en diferentes áreas de la sociedad, como la educación y la asistencia social. Aquí la política partidaria no aparece como un objetivo explícito de sus líderes, sino como un espacio indirecto de influencia restringido a iniciativas individuales. Veamos un poco más en qué consisten estos dos vectores de proyección religiosa.

El primero de ellos se encuentra restringido exclusivamente al plano religioso, o sea, a la dimensión de lo sagrado; se trata del Ministerio a las naciones como una de las áreas más significativas de crecimiento internacional de Rey de Reyes a través de prédicas, cruzadas y campañas del pastor y su mujer en países de los cinco continentes. El matrimonio Freidzon logra proyectarse bajo la figura de los evangelistas portadores del "avivamiento espiritual" de la Argentina. Este trabajo se traduce naturalmente en donaciones de las iglesias extranjeras que contribuyen a la construcción de nuevos proyectos, como es el caso, por ejemplo, de la universidad cristiana. Sólo por nombrar algunos de los destinos realizados en este año (2009), podemos señalar que Claudio Freidzon predicó dos veces en Estados Unidos (una en Dallas y

Debates do NER, Porto Alegre, ano io, N. I6, P. 7I-94, JUl./Dez. 2009 
otra en New Jersey), una en Málaga, España, una Finlandia, otra en Paris, Francia, Colombia y Suiza, mientras que su esposa Betty, participó de un evento en Costa Rica. El reverso de las campañas en el extranjero es la Conferencia Internacional de Avivamiento Breakthrough -Irrumpiendo- que ofrece el pastor Freidzon en las instalaciones de su iglesia desde 1998. Allí se reúnen a figuras locales, como Carlos Annacondia y el Reverendo Sergio Scataglini, con pastores de América Latina y Estados Unidos, durante cuatro días de oración y alabanza marcados por la presencia de milagros, curaciones y profecías. El público de este evento no es la congregación de Rey de Reyes, sino cristianos de otros países que se acercan a conocer la experiencia local. Por eso, los idiomas oficiales de la conferencia son el español, el inglés y el portugués. Es importante reconocer que las condiciones de posibilidad del Breakthrough descansan en las tres posiciones de sujeto que estabiliza el sistema celular, configurando una técnica de gobierno eficiente. De ahí, que el último día se encuentre dedicado a difundir el modelo de organización eclesiástica como un ejemplo exitoso y por lo tanto imitable de iglesia en continuo crecimiento.

El segundo vector de proyección religiosa que mencionamos tiene que ver con la posibilidad de intervenir en diferentes dominios de la sociedad. Una vez que las mega-iglesias logran consolidarse internamente, tienden a formar diferentes ministerios. Estos constituyen la unidad organizativa de actividades en las que se especializa la institución. Se trata de grupos de trabajo definidos en primera instancia por la tarea que los convoca, otorgándoles una identidad diferencial vinculada a proyectos, objetivos, estrategias, responsabilidades, roles y, en algunos casos, la administración de recursos materiales. A partir del 2001 los dos conceptos dominantes que trazan las coordenadas de acción de un conjunto delimitado de ministerios consisten en: la Asistencia Social y la Educación. La forma en que la iglesia se propone intervenir activamente en la sociedad es a través de la atención, por un lado, de las necesidades materiales de sectores desfavorecidos y familias en situación de calle y la apuesta, por el otro, a la formación intelectual de una "nueva generación de líderes" educados en circuitos evangélicos. La Fundación, el Buenos Aires Christian School, el proyecto de la universidad y

Debates do NER, Porto Alegre, Ano io, N. I6, P. 7I-94, JUl./Dez. 2009 
en menor medida la Escuela de vida y de líderes, cristalizan el impulso vigente de la iglesia hacia el trabajo social y la capacitación profesional. Aquí reside una suerte de formula política de Rey de Reyes, no en términos partidarios, sino en el sentido de un avance sobre los problemas sociales de la Argentina y sobre sus estructuras de poder. Mientras que el pastor Carnival de la Catedral de la Fe decidió en su momento apoyar las marchas de Blumberg o el reverendo Prein del Centro Cristiano Nueva Vida no duda en respaldar al gobierno durante el conflicto del campo, Freidzon se mantiene ajeno a la coyuntura política y al juego de las alianzas. Sus esfuerzos, los del núcleo duro, se encuentran abocados al desarrollo de espacios de formación profesional que proyecten a una nueva camada de jóvenes hacia las posiciones de influencia de la sociedad.

\section{CONCLUSIONES: LAS MEGA-IGLESIAS COMO ORGANIZACIONES TRASNACIONALES}

Los procesos globalizadores refieren tanto a la autonomización sin precedentes del capital financiero y la circulación de mercancías, como a la difusión de objetos culturales, símbolos, prácticas y representaciones. Para desarrollar una mirada más profunda del juego de interdependencias transnacionales, es preciso tener en cuenta el doble movimiento que produce la globalización: por un lado, des-localización de prácticas, representaciones, creencias y costumbres locales; por otro, re-localización dentro de un universo más vasto de intercambio global (Robertson, 2000, p. 225). Los particularismos son la contracara ineludible de la globalización; pero también indican que ambos polos de la relación, es decir, lo particular y lo universal, son constantemente transformados en el juego de intercambios y condicionamientos que intensifican los vínculos de dependencia recíproca más allá de los Estados Nacionales. Los formas de organización religiosa que representan las mega-iglesia evangélicas, pueden ser consideradas como agentes globalizadores al menos en dos sentidos complementarios: por un lado, contribuyen al movimiento de des-localización y re-localización de 
un conjunto de practicas, símbolos, saberes y discursos internacionales. Por ejemplo, el sistema de organización celular que aplica Freidzon es la adaptación del modelo colombiano que a su vez toma elementos de la experiencia coreana del pastor David Yonggi Cho. La diferencia radica en que la actualización local de ese saber experto, como vimos en el primer apartado, no trata de hacer de cada creyente un líder de célula, sino que consolida fuertemente a las posiciones periféricas, transformándolas en el sujeto dominante del universo evangélico. También podríamos hablar de redefiniciones simbólicas en el modo en que se configura el discurso de la prosperidad, la sanidad interior y la guerra espiritual. Por otro lado, las mega-iglesias no sólo son receptoras sino también productoras de bienes culturales de exportación, reforzado por un juego de afinidades electivas con la lógica de producción cultural del capitalismo tardío, como pudimos analizar en otro trabajo (Algranti, 2007, p. 121-129). Aquí juega un papel destacado la proyección internacional de los pastores como figuras evangelísticas, capaces de insertarse en el mercado de oferta y demanda simbólica que definen los circuitos ampliados del neo-pentecostalismo. En este sentido, las conferencias Breakthrough permiten posicionar a Rey de Reyes como un modelo exitoso y por lo tanto replicable de organización en continuo crecimiento. La síntesis singular que lleva a cabo una institución a través del juego de reelaboraciones por las que matiza a las influencias externas e internas de los espacios religiosos que contribuyen a moldearla, termina convirtiendo a esta síntesis en una experiencia única en su tipo, pero de las que se pueden extraer principios generales.

Entender a las mega-iglesias como organizaciones trasnacionales significa comprender el modo sui generis en que resuelven la articulación entre lo global y lo local, participando en el régimen de circulación de flujos internacionales en su doble función de consumidoras y productoras de bienes simbólicos (objetos culturales, personas sagradas, discursos, figuras simbólicas, imágenes y saberes expertos). Esta articulación se expresa finalmente en un cosmos más o menos estable de relaciones y posiciones que los sujetos se apropian, reproducen y modifican, hasta convertirlas en el orden natural de las cosas.

Debates do NER, Porto Alegre, Ano io, N. I6, P. 7I-94, JUl./Dez. 2009 


\section{REFERÊNCIAS BIBLIOGRÁFICAS}

ALGRANTI, Joaquín. Globalización Religiosa y reencantamiento del mundo. Estudio sobre la afinidad electiva entre el capitalismo y el universo pentecostal, In: ARONSON, Perla. Notas para el estudio de la globalización: un abordaje multidimensional de las transformaciones sociales contemporáneas, Buenos Aires: Editorial Biblos, 2007. p. 107-135.

ALVES, Daniel (2008) A religião em rede: contribuições teóricas e metodológicas para um estudo sobre relaçóes transnacionais entre agentes religiosos pentecostais. In: $32^{\circ}$ ENCONTRO ANUAL DA ANPOCS, Caxambu-MG, 27-31 de Outubro, 2008.

APPADURAI, Arjun. La modernidad desbordada. Dimensiones culturales de la globalización, Buenos Aires: Fondo de Cultura Económica, 2001.

BIRMAN, Patricia. Conexões políticas e bricolagens religiosas: questôes sobre o pentecostalismo a partir de alguns contrapontos. In: SANCHIS, Pierre (org.) Fieis \& Cidadãos. Percursos de sincretismo no Brasil, Rio de Janeiro: EdUERJ, p. 959-87, 2001.

BOURDIEU, Pierre. El sentido práctico, Buenos Aires: Siglo XXI, 2007.

DOUGLAS, Mary. Estilos de pensar: ensayos críticos sobre el buen gusto. España: Gedisa, 1998.

FOUCAULT, Michel. Omnes et singulatim: hacia una crítica de la razón política, In: La vida de los hombres infames. Montevideo, Nordan-comunidad Altamira, p. 205-307, 1992.

GUIGOU, Nicolás. El dinero en el proceso de integración y desarrollo de las iglesias pentecostales brasileñas en el Uruguay. Sociedad y Religión, Buenos Aires, $\mathrm{N}^{\circ} 10 / 11,1993$.

GODELIER, Maurice. El enigma del don. Barcelona: Paidós, 1998.

GRAMBY-SOBUKWE, Sharon y HOILAND, Tim. The Rise of Mega-Church Efforts in International Development: A Brief Analysis. Transformation, Vol. 26, No 2, pp. 104-117, 2009.

HERVIEU-LÉGER, Danièle. El peregrino y el convertido: La religión en movimiento. México: Instituto Cultural Helénico, 2004.

Debates do NER, Porto Alegre, ano io, N. I6, P. 7I-94, JUl./Dez. 2009 
ORO, Ari. Pedro. Podem passar a sacolinha: um estudo sobre as representaçóes do dinheiro no neopentecostalismo brasileiro. Cadernos de Antropologia, Vol. 9, p. 7-44, 1992.

ORO, Ari Pedro \& STEIL, Carlos Alberto (orgs.). Globalização e Religiāo. Petrópolis: Vozes, 1997.

PACE, Enzo. Salvation Goods, the Gift Economy and Charismatic Concern. Social Compass, vol 53, n. 1, p. 49-64, 2006.

MARIANO, Ricardo. Os Neopentecostais e a Teología da Prosperidade. Novos Estudos, 44, 1996.

MAUSS, Marcel. Sociología y Antropología, Madrid: Tecnos, 1979.

MALLIMACI, Fortunato. Creer por su propia cuenta en la ciudad de Buenos Aires. In: FORNI, Floreal; MALLIMACI, Fortunato y CÁRDENAS, Luis (coord.) Guía de la diversidad religiosas de Buenos Aires, T. II, Buenos Aires, Biblos, p. 1533, 2008.

ROBERTSON, Robert. Glocalización: tiempo-espacio y homogeneidadheterogeneidad. Zona Abierta No 92-93. Madrid. p. 213-241, 2000.

SEGATO, Rita Laura. La faccionalización de la república y el paisaje religioso como índice de una nueva territorialidad, In: ALONSO, Aurelio (comp.) América Latina y el Caribe. Territorios religiosos y desafíos para el diálogo. Buenos Aires, CLACSO, 2008, p. 41-80.

SEMÁN, Pablo. La recepción popular de la Teología de la Prosperidad. Scripta Ethnologica, Buenos Aires, Vol. XXIII, p. 145-162, 2001.

THUMMA, Scott y DAVE, Travis. Beyond Megachurch Myths: What We Can Learn from America’s Largest Churches. Jossey-Bass publisher, 2007.

TURNER, Víctor. La selva de los símbolos. Madrid: Siglo XXI, 1999. 